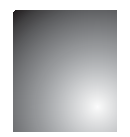

\title{
Conceitos Atribuídos À Sustentabilidade em Organizações de Diferentes Setores
}

\author{
Concepts Attributed to Sustainability in Organizations from \\ Different Sectors
}

\author{
Sabrina Soares da Silva \\ Professora adjunta do Departamento de Administração e Economia. Universidade Federal de Lavras. Lavras, MG. Brasil. E-mail: \\ sabrinasosil@yahoo.com.br
}

\section{Ricardo Pereira Reis}

Professor do Departamento de Administração e Economia. Universidade Federal de Lavras. Lavras, MG. Brasil. E-mail: ricpreis@ufla.br

\section{Robson Amâncio}

Professor adjunto da Universidade Federal Rural do Rio de Janeiro. Seropédica, RJ. Brasil. E-mail: robson.amancio@uol.com.br

\section{Resumo}

O termo sustentabilidade surgiu nas áreas de Biologia e Ecologia, porém, seu uso indiscriminado e acrítico tem feito com que sua adoção não se aproxime da sua definição original. Esse estudo teve como objetivo discutir os diferentes conceitos atribuídos à sustentabilidade nas organizações, descrevendo os significados a ela atribuídos. Foram adotados, como objeto de estudo, os relatórios de sustentabilidade e os conteúdos dos sítios eletrônicos de oito organizações. Foi observada grande discrepância entre os conceitos atribuídos à sustentabilidade, estando a maior parte das ideias associada à permanência da própria empresa. As preocupações com o ambiente se restringiram à redução do uso de recursos naturais ou do impacto ambiental. Já as preocupações sociais se resumiram a diferentes formas de investimentos, programas e ações sociais. A maior parte das organizações buscou se amparar no termo sustentabilidade para legitimar sua atuação, provocando um esvaziamento desse conceito ao reduzi-lo ao atendimento dos interesses da própria organização.

Palavras-chave: Sustentabilidade. Discursos Organizacionais. Transposição de Conceitos. Legitimidade. Permanência Organizacional.

\section{Abstract}

The term sustainability has emerged in Biology and Ecology fields, however, the indiscriminate and uncritical use of it had made its adoption diverge from the original definition. This study aims to discuss the different concepts attributed to sustainability in organizations, describing the meanings assigned to it. The object of study adopted was the sustainability reports and websites of eight organizations. It was observed large discrepancy between the concepts associated to sustainability. Most of the ideas associated with sustainability were related to the permanence of the company itself. Environment concerns were restricted to the reduction of natural resources use or to the impact on the environment. Social concerns were related to different forms of investments, programs and social activities. Most organizations are using the term sustainability in order to legitimize their operations, causing a weakening of this concept by restricting it to the maintenance of organization interests.

Keywords: Sustainability. Organizational Discourse. Transposition of Concepts. Legitimacy. Organizational Permanence. 


\section{INTRODUÇÃo}

A sustentabilidade, embora venha sendo amplamente discutida nos últimos anos, não possui um conceito aceito e consolidado. Esse termo costuma estar associado ao desenvolvimento sustentável que, desde a publicação do Relatório Nosso Futuro Comum, passou a ser definido como "[...] aquele que atende às necessidades do presente sem comprometer a possibilidade de as gerações futuras atenderem às suas próprias necessidades" (COMISSÃO MUNDIAL SOBRE MEIO AMBIENTE E DESENVOLVIMENTO - CMMAD,1991, p. 46). Porém, a noção de sustentabilidade não se resume à sua relação com o desenvolvimento.

A origem etimológica da sustentabilidade encontra-se em um forma derivada do verbo sustentar, que seria similar a manter (REDCLIFT, 1994). Entre cientistas de língua hispânica, costuma-se discutir a tradução correta do termo em duas frentes: a primeira, acredita que sustentabilidade deriva de sostenibilidad, de sostener, que significa ser mantido; a segunda, defende que sua origem é sustentabilidad, de sustentar, que indica manter (BECKER, 1997). No meio científico, o termo sustentabilidade surgiu nas áreas de Biologia e Ecologia, representando a capacidade que um ecossistema possui de manter um equilíbrio dinâmico que permita a subsistência da maior biodiversidade possível, incluindo todas as espécies. (BOFF, 2010)

Porém, o uso indiscriminado e acrítico do termo sustentabilidade nos últimos anos faz com que sua adoção se afastasse cada vez mais dessa definição. A amplitude com que o conceito é utilizado faz com que praticamente todas as correntes de pensamento concordem com a ideia de que a sustentabilidade deve orientar as decisões envolvendo o ambiente e ser um preceito básico para nortear as ações dos indivíduos e organizações. Dessa forma, esse termo passou a ser utilizado, muitas vezes, como um simples atributo retórico ou um recurso linguístico para dissimular a defesa de interesses particulares, que não guardam relação com a noção de sustentabilidade proposta na Biologia e dificultam discussões que atribuam a esse conceito significados mais profundos.

Esse problema ocorre devido à prática, comum na teoria organizacional, de incorporar teorias, modelos e conceitos oriundos de outras disciplinas e áreas. Esse deslocamento, embora possa constituir um meio importante e legítimo de formulação teórica, pode resultar em colocações inapropriadas, descaracterizando ou mutilando o que era originalmente proposto. (GUERREIRO RAMOS, 1981)

Nas organizações, o termo sustentabilidade tem estado presente em diversos discursos que buscam justificar os impactos das diferentes atividades produtivas sobre o ambiente e legitimar sua atuação frente à sociedade. Por isso, segundo Andrade (2001), as estratégias socioambientais não devem ser analisadas apenas sob a dimensão técnico-econômica, mas como um jogo político de busca de legitimidade e vantagem competitiva.

As organizações costumam tratar a sustentabilidade em diferentes conotações, dependendo do contexto no qual ele é inserido. Esse movimento tem sido impulsionado pelo desenvolvimento das legislações ambientais e por uma maior cobrança por parte dos indivíduos para que as empresas busquem compensar os impactos que sua ação causa, não apenas no meio social, mas também no ambiente como um todo. Segundo Vieira et al. (2013), o estudo do uso de nomenclatura ligada à prática de ações sociais nas organizações é relevante por auxiliar na compreensão desse fenômeno, especialmente no contexto brasileiro. Contudo, estudos como esse ainda não são comuns e a discussão do uso do termo sustentabilidade nas organizações, realizada nesse estudo, busca contribuir para o preenchimento dessa lacuna na literatura.

Considera-se que as organizações buscam justificar suas ações frente a sociedade, utilizando diferentes estratégias de comunicação, sendo uma das principais a elaboração de relatórios de sustentabilidade. Esses relatórios têm como objetivo divulgar o desempenho social, ambiental e econômico das organizações. Para a Global Reporting Initiative (GRI, 2006, p. 3), “[...] elaborar relatórios de sustentabilidade é a prática de medir, divulgar e prestar contas para os stakeholders internos e externos do desempenho organizacional visando ao desenvolvimento sustentável". Esses relatórios configuram o posicionamento formal dos indivíduos que atuam nas organizações, refletindo a visão compartilhada nesses ambientes. Também dão indícios sobre como a sustentabilidade é conceituada, assim como das principais ideias associadas a esse termo, o que é relevante para que se compreenda como 
as organizações têm buscado incorporar as questões socioambientais em seus discursos e em suas práticas.

Com base nesses relatórios, esse estudo buscou discutir os diferentes conceitos atribuídos à sustentabilidade nas organizações, descrevendo os significados a ela atribuídos. Os resultados puderam indicar como as organizações têm respondido às atuais demandas socioambientais e que medidas vêm tomando com o intuito de se tornarem mais sustentáveis.

\section{Comprometimento das Organizações com as Questões Socioambientals}

Ao longo dos últimos anos as organizações têm buscado adotar uma postura mais preocupada com os diversos problemas socioambientais. Essa mudança de postura tem sido impulsionada pelo desenvolvimento da legislação ambiental e maior cobrança da sociedade e do mercado, além de fatores internos à própria organização (PÉREZ-LÓPEZ; MORENO-ROMERO; BARKEMEYER, 2013). Segundo Gomes et al. (2010), a preocupação com os impactos sociais e ambientais, antes calcada no altruísmo e na caridade, assumiu recentemente uma concepção estratégica. Griesse (2007) acrescenta que, no Brasil, devido às desigualdades sociais e econômicas, ações dessa natureza tornam o papel das organizações ainda mais importantes.

Uma das primeiras formas pelas quais se buscou indicar uma maior preocupação nas organizações com a sociedade e o ambiente como um todo foi através da responsabilidade social. Segundo Carroll (1999), foi na década de 1950 que a noção responsabilidade social corporativa passou a ser discutido. Foi nessa época que Bowem (1953) conceituou este termo como o conjunto de obrigações dos executivos na adoção de políticas e ações que fossem favoráveis para a sociedade como um todo e não apenas para a própria empresa. Recentemente, obteve destaque o conceito elaborado pelo Instituto Ethos:

Responsabilidade social empresarial é a forma de gestão que se define pela relação ética $e$ transparente da empresa com todos os públicos com os quais ela se relaciona e pelo estabelecimento de metas empresariais que impulsionem o desenvolvimento sustentável da sociedade, preservando recursos ambientais $e$ culturais para as gerações futuras, respeitando a diversidade e promovendo a redução das desigualdades sociais. (INSTITUTO ETHOS, 2010)

Ashley (2005) acrescenta que exercer a responsabilidade social permite o desenvolvimento de canais de relação entre a empresa e seus stakeholders, por meio de princípios que expressam preocupação com os seguintes aspectos:

a) o desenvolvimento do ser humano, incluindo o respeito à sua cultura, valores e direito à liberdade de pensamento e expressão;

b) condições saudáveis de trabalho, remuneração justa, capacitação profissional, realização pessoal, direito ao diálogo e maior liberdade na tomada de decisões;

c) transparência e ética, considerando o interesse coletivo na condução dos negócios;

d) o meio ambiente, com zelo, gestão adequada de seus recursos e oferta de produtos ecologicamente corretos;

e) a excelência na fabricação de produtos e prestação de serviços, com postura ética e sem causar prejuízo aos consumidores; $e$

f) o desenvolvimento científico, cultural, esportivo, educacional e comunitário.

Estudos, como o de Nakayama e Teixeira (2012), buscam compreender como as estratégias e ações de responsabilidade social são compreendidas nas organizações. No estudo dessas autoras, na empresa "O Boticário", foram identificados valores e crenças como valorização dos funcionários, respeito às leis, transparência e confiança. Também se mostrou evidente a preocupação dos dirigentes com a legitimidade da empresa frente à sociedade. Recentemente, a responsabilidade social passou a ser denominada, por alguns autores, como responsabilidade socioambiental, na busca de se incluir preocupações ambientais àquelas sociais nas organizações.

Outros conceitos que buscam refletir preocupações socioambientais também vêm sendo encontrados com maior frequência no meio empresarial. A filantropia empresarial, por exemplo, tem sido frequentemente adotada. Ela pode ser vista, fundamentalmente, como um ato econômico, por se orientar por interesses $e$ lucros da própria empresa, mas possui também dimensões sociais, por envolver preocupações altruístas 
e políticas, se relacionando à imagem organizacional (HIMMELSTEIN, 1997; LONDON, 1991). Ainda que seja associada a maior lucratividade, nem sempre os investimentos socioambientais podem ser relacionados a retornos anormais (NOSSA et al., 2009). A filantropia é também caracterizada, segundo Tenório (2006), como uma ação assistencialista predominantemente temporária. Assim, costuma se resumir a doações de recursos financeiros ou materiais.

Outra forma de atuação organizacional que reflete preocupações sociais é a cidadania empresarial. Segundo Tenório (2006) essa forma de atuação reflete o envolvimento da organização em programas sociais, como o voluntariado, o compartilhamento de capacidade gerencial, parcerias com associações ou fundações e investimentos em projetos sócio-ambientais. Becker (2009) acrescenta que o conceito de cidadania empresarial tornou-se de uso corrente na década de 1990 para designar os investimentos da iniciativa privada em ações sociais, ou os investimentos privados com fins públicos, aplicados em organizações não governamentais, fundações e outras entidades sem fins lucrativos.

Embora apenas a responsabilidade social seja vista como uma forma de atuação que não se resume a investimentos isolados (ASHLEY, 2005), também os investimentos socioambientais de caráter filantrópico ou cidadão são considerados positivos e desejáveis, diante da atual conjuntura, com diversos casos de degradação ambiental e deterioração social. Essas formas de atuação podem ser vistas como respostas das organizações às diferentes demandas sociais $e$ ambientais, ainda que não diretamente relacionadas às suas atividades principais.

Quando as organizações buscam responder às demandas específicas de seus acionais, a atuação mais comum é a ligada às boas práticas de governança corporativa. A noção de governança corporativa surgiu, segundo o Instituto Brasileiro de Governança Corporativa (IBGC, 2010), para superar o conflito de agência decorrente da separação entre a propriedade e a gestão empresarial. Esse conflito surge da falta de alinhamento entre os interesses do proprietário (acionista) e os do agente (executivo). A governança corporativa tem como objetivo criar mecanismos que assegurem que o comportamento do agente esteja alinhado com o interesse do proprietário.
A boa governança proporciona aos proprietários a gestão estratégica de sua empresa e a monitoração da direção executiva, o que se torna possível a partir de ferramentas como o conselho de administração, a auditoria independente e o conselho fiscal. A organização que opta pelas boas práticas de governança corporativa se orienta pela transparência, a prestação de contas, a equidade e a responsabilidade corporativa. Juntas, tais práticas buscam evitar problemas, como abusos de poder do acionista controlador sobre minoritários, da diretoria sobre os acionistas e dos administradores sobre terceiros, assim como erros estratégicos, decorrentes de muito poder concentrado no executivo principal, e fraudes, a partir do uso de informação privilegiada em benefício próprio. (IBGC, 2010)

Ainda entre as respostas da organização aos interesses de mercado, mas atendendo também a exigências legais, foram desenvolvidos os conceitos de produção mais limpa e ecoeficiência, como uma forma de refletir mudanças nos processos produtivos. O conceito de produção mais limpa está associado à adoção de uma estratégia ambiental, preventiva $e$ integral, que garanta que os processos produtivos prevejam ou reduzam os riscos de curto e longo prazo para a humanidade e o ambiente (DIAS, 2009). Esse posicionamento adota os seguintes procedimentos:

Quanto aos processos de produção: conservando as matérias-primas e a energia, eliminando aquelas que são tóxicas e reduzindo a quantidade e a toxicidade de todas as emissões $e$ resíduos. Quanto aos produtos: reduzindo os impactos negativos ao longo do ciclo de vida do produto, desde a extração das matérias-primas até sua disposição final, através de um design adequado aos produtos. Quanto aos serviços: incorporando as preocupações ambientais no projeto e fornecimento dos serviços. (DIAS, 2009, p. 127)

Esses procedimentos tornariam mais racionais o uso dos recursos ambientais, conceito similar ao de ecoeficiência. Esse último foi inicialmente desenvolvido, inicialmente, por Schaltegger e Sturm (1989) e, posteriormente, difundido pelo World Business Council for Sustainable Development (WBCSD). Ecoeficiênicia pode ser definida como aquela que é obtida pela entrega de mercadorias e serviços, a preços competitivos, que satisfaçam às necessidades humanas e tragam 
qualidade de vida, enquanto reduzem os impactos ecológicos e a intensidade do uso de recursos, para um nível alinhado à capacidade estimada de sustentação da Terra (SCHMIDHEINY, 1992). Esse conceito possui três objetivos centrais:

1. Redução do consumo de recursos: inclui minimizar a utilização de energia, materiais, água e solo, favorecendo a reciclabilidade $e$ a durabilidade do produto $e$ fechando o ciclo dos materiais.

2. Redução do impacto na natureza: inclui a minimização das emissões gasosas, descargas líquidas, eliminação de desperdício e a dispersão de substâncias tóxicas, assim como impulsiona a utilização sustentável de recursos renováveis.

3. Melhoria do valor do produto ou serviços: o que significa fornecer mais benefícios aos clientes, através da funcionalidade, flexibilidade e modularidade do produto, oferecendo serviços adicionais e concentrando-se em vender as necessidades funcionais de que, de fato, os clientes necessitam, o que levanta a possibilidade de o cliente receber a mesma necessidade funcional com menos materiais e menor utilização de recursos. (DIAS, 2009, p. 130-131)

Tanto a produção mais limpa como a ecoeficiência podem ser favorecidas por mudanças produtivas decorrentes de inovações nas diferentes fases do processo produtivo. Essas diferentes formas de preocupação socioambiental por parte das organizações têm sido associadas à sustentabilidade organizacional, ainda que a sustentabilidade, em seu conceito originado derivado da Biologia, esteja mais associada à manutenção do ecossistema como um todo, e não apenas da organização e dos recursos necessários para a manutenção de sua produtividade e lucratividade.

As preocupações que levam as empresas a adotarem práticas ambientalmente corretas são diversas. Carvalho, Machado e Meirelles (2011), por exemplo, identificaram que as organizações do setor siderúrgico, influenciadas por mudanças climáticas e aquecimento global, buscam maior eficiência, qualidade e adequação às exigências ambientais. Essas organizações adotaram justificativas ambientais, além de outras, para adotar mudanças como o reflorestamento, cogeração de energia, reaproveitamento de resíduos e outras melhorias no processo de produção do carvão. Contudo, segundo Vieira et al. (2013), desde a década de 1990 arguenta-se que as ações sociais nas organizações não seriam totalmente altruístas, pois visavam melhorar seu desepenho em longo prazo.

A noção de sustentabilidade é mais dificilmente associada à organização, visto que a maior parte dos autores que a discutem não acreditam na possibilidade de uma organização que possa ser efetivamente sustentável. Keinert (2007) considera que a sustentabilidade é, hoje, uma utopia, no sentido em que é impossível, em um dado contexto, mas que pode se tornar real e tangível, a partir de inovações nos mais diversos campos, como organizacionais, gerenciais, tecnológicos, no modo de vida pessoal e na interação social. Para essa autora, nada poderia acontecer sem a mudança de mentalidade e sem a crença na existência de um futuro comum. E essa mudança de mentalidade refletir-se-ia em mudanças nas ações humanas. A sustentabilidade estaria, então, ligada a uma noção de coletividade que vai muito além daquela presente nas outras formas de atuação organizacional com fins socioambientais, pois essas têm finalidade predominantemente individualista.

Para que exista sustentabilidade, princípios mínimos de austeridade, sobriedade e simplicidade precisam prevalecer, de forma que sejam respeitados os limites impostos pela disponibilidade de recursos ambientais. Essa seria a única maneira de se tentar minimizar a ação da segunda lei da termodinâmica no processo econômico, com sua inevitável degradação entrópica. Porém, os mecanismos de mercado, que tornam o lucro imediato o objetivo principal da economia moderna, fazem com que muitos recursos sejam utilizados de maneira exaustiva e com que as pessoas adquiram muito mais bens do que realmente precisam (CAVALCANTI, 1998). Nesse sentido,

[...] sustentabilidade significa a possibilidade de se obterem continuamente condições iguais ou superiores de vida para um grupo de pessoas e seus sucessores em dado ecossistema. Numa situação sustentável, o meio ambiente é menos perceptivelmente degradado, embora, como saibamos, o processo entrópico nunca cesse, procedendo invisível e irrevogavelmente levando ao declínio inflexível do estoque de energia disponível na terra. [...] O conceito de sustentabilidade equivale à idéia de manutenção de nosso sistema de suporte da vida. Ele significa comportamento que procura obedecer às leis da natureza. Basicamente, trata-se do reconhecimento do que é biofisicamente 
possível em uma perspectiva de longo prazo. (CAVALCANTI, 1998, p. 165)

\section{Procedimentos Metodológicos}

Essa pesquisa, de abordagem qualitativa, é classificada como descritiva, quanto aos fins, e documental, quanto aos meios. Foram adotados, como objeto do estudo, relatórios de sustentabilidade e, complementarmente, os conteúdos disponibilizados nos sítios eletrônicos das organizações estudadas. Segundo Amran, Lee e Devi (2013), as organizações buscam incorporar em sua identidade práticas relacionadas à sustentabilidade, o que pode ser evidenciado em seus relatórios de sustentabilidade. Optou-se por esses documentos por constituírem uma forma de comunicação oficial das organizações, na qual se observa o posicionamento dos indivíduos com relação ao meio ambiente, seu entendimento sobre sustentabilidade $e$ as ações que, na organização, são relacionadas a esses assuntos. Eberle, Berens e Li (2013) reforçam a importância desse tipo de comunicação ao concluírem que o uso de canais de comunicação para assuntos relacionados à responsabilidade social pode aumentar a reputação das organizações.

As organizações estudadas foram selecionadas entre aquelas cujos relatórios de sustentabilidade foram considerados os melhores, no ano de 2010, pelo GRI Readers' Choice Awards (GRI, 2010). Todas as organizações brasileiras que foram premiadas como uma das cinco primeiras colocadas, em cada categoria, foram incluídas nesse estudo, conforme disposto no Quadro 1. Foram analisados os relatórios de sustentabilidade, ou relatórios similares, dessas organizações (BANCO DO BRASIL, 2008; BRADESCO, 2008; CENTRAIS ELÉTRICAS BRASILEIRAS, 2010b; CENTRAIS ELÉTRICAS DE FURNAS, 2008; FUNDAÇÃO BRADESCO, 2008; ITAIPU BINACIONAL, 2008; NATURA, 2008; VALE, 2008), assim como os conteúdos de seus sítios eletrônicos. (BANCO DO BRASIL, 2010; BRADESCO, 2010; CENTRAIS ELÉTRICAS BRASILEIRAS, 2010; CENTRAIS ELÉTRICAS DE FURNAS, 2010; FUNDAÇÃO BRADESCO, 2010; ITAIPU BINACIONAL, 2010; NATURA, 2010; VALE, 2010)

\begin{tabular}{ll}
$\begin{array}{l}\text { Prêmio Engajamento } \\
\text { Banco do Brasil - Brasil }\end{array}$ & Prêmio Sociedade Civil \\
Polymer Group, Inc. & Vale - Brasil \\
(PGI) - EUA & Eletrobrás - Brasil \\
Fundação Bradesco - Brasil & Itaipu Binacional - Brasil \\
Grupo Los Globo & Eletrobrás Furnas - Brasil \\
Agr. - Argentina & Natura - Brasil \\
Larsen \& Toubro (L\&T) - Índia & \\
\hline $\begin{array}{l}\text { Prêmio Cadeia de Valor } \\
\text { Natura - Brasil }\end{array}$ & Prêmio Investidor \\
Banco do Brasil - Brasil & Banco do Brasil - Brasil \\
Arcor SAIC - Argentina & Bradesco - Brasil \\
Apple - EUA & Vale - Brasil \\
Larsen \& Toubro (L\&T) - Índia & 3M - EUA \\
Fencedor - EUA \\
Banco do Brasil - Brasil & Prêmio Relatório Mais Eficaz \\
Vale - Brasil & Bradesco - Brasil \\
Bradesco - Brasil & Itaipu Binacional - Brasil \\
Eletrobrás Furnas - Brasil & Eletrobrás Furnas - Brasil \\
Natura - Brasil & Walmart Stores - EUA \\
\hline
\end{tabular}

Quadro 1: Melhores relatórios de sustentabilidade segundo a GRI em 2010

Fonte: GRI (2010)

Os dados foram analisados com base em técnicas de análise de conteúdo, por meio das quais se buscou compreender o sentido da comunicação, mas permitindo que se desviasse o olhar para uma outra significação, que poderia se manifestar por trás da mensagem principal (BARDIN, 2004). Na análise de conteúdo, o texto é considerado um meio de expressão do sujeito, onde o analista busca categorizar as unidades de texto inferindo uma expressão que as representem (CAREGNATO; MUTTI, 2006). Segundo Bauer (2002), a análise de conteúdo trabalha, tradicionalmente, com materiais textuais escritos, como os adotados como objeto de análise nesse estudo.

Seguindo as sugestões de Bardin (2004), a primeira fase da análise consistiu em uma pré-análise, na qual foi feita uma leitura de todo o material, permitindo sistematizar as primeiras impressões sobre seu conteúdo. Em seguida, foi feita a exploração do material, quando foi elaborada sua codificação, agregando os dados em unidades de registro e contexto. As unidades de registro constituíram os segmentos de conteúdo que continham um ideia completa sobre os conceitos de sustentabilidade contidos nos discursos analisados. As unidades de contexto são associações feitas entre as unidades de registro e uma determinada categoria. 
Nesse caso, as categorias eram os significados atribuídos à sustentabilidade nos discursos organizacionais. Essas categorias foram construídas com base no Referencial Teórico adotado, ao mesmo tempo em que, em um processo circular, levaram à construção desse Referencial. Buscou-se incluir na análise toda referência feita aos termos "sustentabilidade", "sustentável" ou outros similares e teve-se o cuidado de separar todo o conteúdo referente à unidade de registro, de modo que cada fragmento contivesse uma ideia completa de como o termo estava sendo utilizado.

Na terceira e última fase, foi feito o tratamento dos resultados obtidos e foram verificadas sua significância $e$ validade. Buscou-se descrever os diferentes significados atribuídos à sustentabilidade nas organizações estudadas que constituíram as categorias, para buscar compreender como a sustentabilidade era entendida nas organizações. Além dos conceitos associados à sustentabilidade, buscou-se identificar o que, nos discursos, deveria ser sustentado ou sustentável.

\section{Resultados e Análises}

A partir da análise dos relatórios de sustentabilidade e de alguns conteúdos disponíveis nos sítios eletrônicos das organizações, foi possível identificar as visões compartilhadas nas organizações estudadas e que sintetizavam como a sustentabilidade era conceituada. Os conceitos atribuídos à sustentabilidade foram bastante diversos e representavam preocupações divergentes, conforme disposto no Quadro 2.

\begin{tabular}{|l|l|}
\hline \multicolumn{1}{|c|}{ Organização } & \multicolumn{1}{c|}{ VISÃo DA SUSTENTABILIDADE } \\
\hline Banco do Brasil & $\begin{array}{l}\text { Conciliar os interesses dos } \\
\text { acionistas ao desenvolvimento } \\
\text { social e ambiental sustentáveis }\end{array}$ \\
\hline $\begin{array}{l}\text { Fundação } \\
\text { Bradesco }\end{array}$ & $\begin{array}{l}\text { Noção de interdependência e } \\
\text { respeito à diversidade }\end{array}$ \\
\hline Natura & $\begin{array}{l}\text { Crescimento econômico aliado às } \\
\text { necessidades sociais e ambientais }\end{array}$ \\
\hline Vale & $\begin{array}{l}\text { Operador sustentável, catalisador } \\
\text { do desenvolvimento local e agente } \\
\text { global de sustentabilidade }\end{array}$ \\
\hline Bradesco & $\begin{array}{l}\text { Finanças sustentáveis, gestão responsável } \\
\text { e investimentos socioambientais }\end{array}$ \\
\hline Eletrobras Furnas & $\begin{array}{l}\text { Assegurar que as metas de lucros } \\
\text { não esgotarão os recursos disponíveis } \\
\text { para futuras gerações }\end{array}$ \\
\hline
\end{tabular}

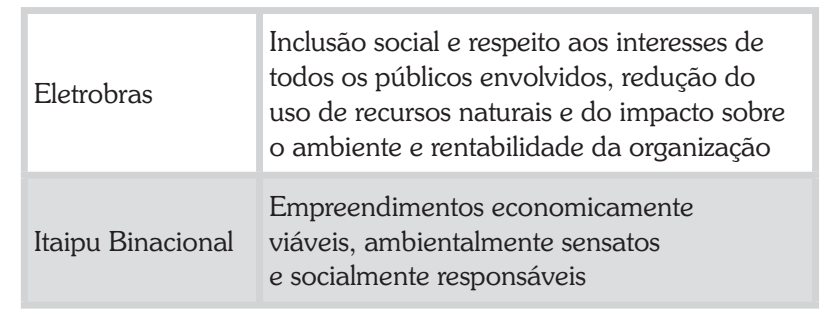

Quadro 2: Visões atribuídas à sustentabilidade nas organizações analisadas

Fonte: Elaborado pelos autores deste artigo

Pode-se observar que a maior parte das organizações define sustentabilidade relacionado-a à permanência da própria organização. Embora o conceito original de sustentabilidade esteja associado a uma maior integração entre a humanidade e a natureza (GLADWIN; KENELLY; KRAUSE, 1995; HOFFMAN; SANDELANDS, 2005; MICKEY, 2007), na qual essas categorias não poderiam ser vistas de maneira dissociada, as preocupações manifestadas nas organizações são, predominantemente, ligadas a uma perspectiva individualista. Isso pode ser observado quando se fala em atender aos interesses dos acionistas, se apontam estratégias para o aumento do número de clientes e serviços (definido como finanças sustentáveis), busca-se um bom relacionamento com os stakeholders e redução de riscos (operador sustentável) ou, ainda, quando se têm como compromissos centrais a rentabilidade da organização, o desenvolvimento de empreendimentos economicamente viáveis e a manutenção de metas de lucros. Em seis das oito organizações analisadas, a sustentabilidade foi associada aos resultados da própria organização, desconsiderando o conceito, elaborado pela Biologia e a Ecologia, que deveria envolver a capacidade de manutenção do equilíbrio dinâmico dentro de um ecossistema como um todo (BOFF, 2010; CAVALCANTI, 1998), ou seja, envolvendo a noção de coletividade.

Porém, há conceitos que se associam um pouco mais a uma visão coletivista, embora ainda limitados. É o que ocorre quando se relaciona sustentabilidade ao desenvolvimento socioambiental, investimentos socioambientais, responsabilidade social e crescimento econômico. Mesmo que tais posicionamentos possam englobar um grupo maior de indivíduos, não se pode dizer que vão garantir a sustentabilidade da organização ou coletiva. Exemplos disso são a ideia de crescimento, que favorece apenas determinados indivíduos, 
por não resultar, necessariamente, em ganhos sociais que sejam compartilhados por toda a humanidade, $e$ investimentos socioambientais e responsabilidade social, que também irão sempre se restringir a um determinado grupo de indivíduos, mesmo que externo às organizações.

As preocupações com o ambiente mostraram-se ainda mais distantes da noção de sustentabilidade desenvolvida na Biologia, por se restringirem a ideias como a de desenvolvimento ambiental, que não pressupõe a evolução natural dos ecossistemas, mas a forma como se intervém nesses sistemas, ou à redução do uso de recursos naturais e do impacto sobre o ambiente, que se restringe à ecoeficiência. Também as visões que sugerem a implantação de empreendimentos ambientalmente sensatos, por se referirem mais à atuação individualista da própria organização, e a utilização dos recursos ambientais de modo a não esgotar os recursos disponíveis para futuras gerações, que se preocupam mais com os recursos utilizados pela própria organização, não se relacionam com a noção original de sustentabilidade.

Ao se observar como as organizações aprofundaram suas visões da sustentabilidade, constatou-se que se mantiveram os mesmos posicionamentos, que indicavam múltiplos significados atribuídos à sustentabilidade e reforçavam o caráter individualista das preocupações organizacionais. Os conceitos relacionados à sustentabilidade nas organizações estão relacionados no Quadro 3, onde também se apresenta o que, segundo os discursos organizacionais, deveria ser sustentado ou sustentável.

Entre os significados atribuídos, nas organizações, à sustentabilidade, o mais recorrente foi o de responsabilidade socioambiental, presente em cinco empresas. Todas essas empresas associaram também a sustentabilidade a investimentos, programas ou ações socioambientais. Esses posicionamentos, apesar de terem um viés coletivista, por indicarem preocupações que vão além do espaço organizacional (ressalta-se que não foram exploradas as intenções por trás dessas ações), não prevêem que os benefícios gerados deveriam atender a todos, sem distinções. Em geral, são pequenos grupos ou localidade que são beneficiadas por esses projetos ou posicionamentos socioambientalmente responsáveis, representando uma coletividade limitada. De maneira similar, uma organização relacionou a sustentabilidade à responsabilidade social e a seus investimentos sociais. Embora a vertente social tenha prevalecido sobre a ambiental, não houve grandes variações em sua perspectiva.

Nessas organizações, a sustentabilidade se resumiria à busca em se ouvir as partes interessadas e buscar incorporar tais práticas no dia a dia. Porém, caso esse público não expressasse que a atuação da organização deveria ser mais sustentável, isso nunca ocorreria. Assim, mesmo relacionando a sustentabilidade a um aspecto coletivista-limitado, não se poderia dizer que tais organizações sejam sustentáveis, visto que apenas se pressupõe o atendimento aos interesses das partes relacionadas e esses podem não representar a coletividade, que envolve seres humanos e não humanos.

Quanto à visão de que a sustentabilidade se resumiria a investimentos e ações socioambientais ou sociais, considera-se que ainda há um distanciamento dos interesses coletivos, por a organização considerar que o compromisso com a sustentabilidade é externo a ela. Ou seja, bastaria, para firmar esse compromisso, que se realizassem investimentos em programas ou projetos que busquem a sustentabilidade, sem que a própria organização viesse a fazer quaisquer alterações em seus processos produtivos ou em sua conduta. É o que acontece, por exemplo, quando se fala em cidadania empresarial e ações voluntárias da organização.

Isso ocorre também quando a organização associa a sustentabilidade à filantropia, o que foi feito por duas empresas. Nesses casos, além de considerar o compromisso com a sustentabilidade externo à própria organização e suas práticas, se resumiu esse conceito a ações pontuais e sem continuidade, conforme conceito de Tenório (2006). Nesses casos, não se pode afirmar que o posicionamento da organização seja sequer socioambientalmente responsável, visto que, além de não sugerir que os diferentes stakeholders estejam sendo ouvidos e seus interesses atendidos, também não se busca qualquer resultado além dos imediatos e limitados. Assim, a noção de longo prazo, que deveria acompanhar a noção de sustentabilidade, é totalmente abandonada. 


\begin{tabular}{|c|c|c|}
\hline ORganizaÇÃo & SigNIFICADOS DA SUSTENTABILIDADE & O QUE DEVE SER SUSTENTADO/SUSTENTÁVEL \\
\hline Banco do Brasil & $\begin{array}{l}\text { Responsabilidade socioambiental } \\
\text { Investimentos socioambientais } \\
\text { Ecoeficiência } \\
\text { Filantropia } \\
\text { Rentabilidade da organização }\end{array}$ & $\begin{array}{l}\text { Desenvolvimento } \\
\text { Negócios } \\
\text { Humanidade } \\
\text { Desempenho } \\
\text { Crescimento dos lucros }\end{array}$ \\
\hline Fundação Bradesco & $\begin{array}{l}\text { Desenvolvimento sustentável das } \\
\text { comunidades pela educação }\end{array}$ & $\begin{array}{l}\text { Educação } \\
\text { Desenvolvimento } \\
\text { Mundo }\end{array}$ \\
\hline Natura & $\begin{array}{l}\text { Liderança e inovação } \\
\text { Novas oportunidades } \\
\text { Sobrevivência da organização } \\
\text { Resultados financeiros } \\
\text { Ecoeficiência } \\
\text { Redução/compensação de impactos ambientais }\end{array}$ & $\begin{array}{l}\text { Desenvolvimento } \\
\text { Valor } \\
\text { Resultados } \\
\text { Destinação dos resíduos } \\
\text { Uso dos insumos } \\
\text { Práticas e modelos }\end{array}$ \\
\hline Vale & $\begin{array}{l}\text { Existência/crescimento da organização } \\
\text { Responsabilidade socioambiental } \\
\text { Investimentos socioambientais } \\
\text { Voluntariado } \\
\text { Criação de valor para as partes } \\
\text { Boas práticas de governança corporativas }\end{array}$ & $\begin{array}{l}\text { Desenvolvimento } \\
\text { Crescimento e liderança da organização } \\
\text { Resultados financeiros } \\
\text { Boa imagem } \\
\text { Valor para as pessoas }\end{array}$ \\
\hline Bradesco & $\begin{array}{l}\text { Responsabilidade socioambiental } \\
\text { Ações socioambientais } \\
\text { Filantropia } \\
\text { Ecoeficiência }\end{array}$ & $\begin{array}{l}\text { Desenvolvimento } \\
\text { País } \\
\text { Finanças } \\
\text { Construções }\end{array}$ \\
\hline Eletrobrás Furnas & $\begin{array}{l}\text { Desenvolvimento } \\
\text { Responsabilidade social } \\
\text { Cidadania } \\
\text { Boas práticas de governança corporativa } \\
\text { Investimentos sociais } \\
\text { Inovação } \\
\text { Lideranças das grandes corporações }\end{array}$ & $\begin{array}{l}\text { Futuro } \\
\text { Desenvolvimento } \\
\text { Des. socioeconômico e local } \\
\text { Iniciativas } \\
\text { Organizações } \\
\text { Crescimento econômico } \\
\text { Uso dos recursos naturais }\end{array}$ \\
\hline Eletrobrás & $\begin{array}{l}\text { Responsabilidade socioambiental } \\
\text { Investimentos socioambientais } \\
\text { Crescimento/rentabilidade organizacional } \\
\text { Ecoeficiência } \\
\text { Boas práticas de governança corporativa } \\
\text { Cumprimento da legislação ambiental }\end{array}$ & $\begin{array}{l}\text { Desenvolvimento } \\
\text { Organização } \\
\text { Gestão } \\
\text { Projetos } \\
\text { Uso dos recursos naturais }\end{array}$ \\
\hline Itaipu Binacional & $\begin{array}{l}\text { Processo de melhoria técnica } \\
\text { Responsabilidade socioambiental } \\
\text { Programas socioambientais } \\
\text { Ecoeficiência }\end{array}$ & $\begin{array}{l}\text { Desenvolvimento } \\
\text { Receitas e lucros } \\
\text { Gestão e práticas } \\
\text { Construções }\end{array}$ \\
\hline
\end{tabular}

Quadro 3: Significados da sustentabilidade e o que deve ser sustentado/sustentável Fonte: Elaborado pelos autores deste artigo 
Também se observa, no Quadro 3, que foi recorrente associar a sustentabilidade à ecoeficiência nos discursos organizacionais. Embora o uso eficiente dos recursos naturais, a reciclagem $e$ o reaproveitamento de materiais (DIAS, 2009; SCHMIDHEINY, 1992) sejam importantes para que a organização reduza seu impacto sobre o ambiente, assume-se uma visão individualista da sustentabilidade, por expressar, primordialmente, preocupação com os ganhos obtidos com essas práticas, seja pela manutenção de uma boa imagem corporativa seja pela redução dos custos. Pode-se também dizer que essas medidas são apenas pontuais e refletem preocupações que se restringem a apenas um recurso natural, afastando-se ainda mais de uma perspectiva coletivista.

O posicionamento individualista das organizações é ainda mais marcante nas associações feitas entre sustentabilidade e a existência, crescimento, rentabilidade ou vantagem competitiva das empresas. Nesses casos, além de se demonstrar preocupações que se restringem à organização, ainda dá ênfase a seu caráter econômico. De maneira similar, associar sustentabilidade à liderança, inovação e melhoria técnica das organizações, está mais relacionado, no discurso das empresas, a preocupações com o desempenho organizacional e seus resultados. Embora tais fatores possam levar a uma redução do impacto da organização sobre o ambiente, nos discursos, eles são mais associados a ganhos para a própria organização e seus acionistas.

A preocupação em transmitir uma boa imagem das organizações para seus acionistas também se destaca quando se relaciona a sustentabilidade às boas práticas de governança corporativa e à criação de valor, o que foi feito por três organizações. Essas práticas refletem a busca de uma equalização entre os interesses dos acionistas das organizações e os de seus executivos (IBGC, 2010). Dessa forma, considerando que o principal interesse dos acionistas seja maximizar o valor da organização, pode-se concluir que a sustentabilidade estaria limitada aos bons resultados financeiros da organização, sem preocupações com seus impactos sobre a sociedade ou o ambiente.

Observou-se ainda, no relatório de uma organização analisada, que se atribuiu à sustentabilidade o significado de cumprimento da legislação ambiental. Essa legislação prevê, entre outras coisas, uma séria de ações para que se minimizem os impactos dos pro- cessos organizacionais sobre o ambiente. Contudo, a organização costuma cumprir a legislação unicamente para evitar punições, demonstrando preocupações individualistas e não com a coletividade. A legislação ambiental, principalmente quando rígida, também costuma sofrer várias críticas dos dirigentes organizacionais, embora talvez seja uma das únicas formas de fazer com que as organizações se comprometam mais com os impactos socioambientais por elas causados. Posicionamento semelhante ocorre quando a sustentabilidade é associada à redução e à compensação dos impactos ambientais da organização, já que nem sempre envolve uma preocupação que vai além do que é legalmente exigido.

Quando se analisa o que deve ser sustentado ou sustentável, nota-se que todas as organizações relatam que o desenvolvimento deve ser sustentável. O grande foco no desenvolvimento vem não apenas da ideia, já bastante difundida, de se associar a sustentabilidade ao desenvolvimento, pela popularização do termo "desenvolvimento sustentável” (CMMAD, 1991), mas também da preocupação das organizações de assumirem uma imagem de que estão contribuindo para o desenvolvimento. Embora nem sempre tenha sido explicitado de que desenvolvimento se estava tratando, foi comum, nos discursos, fazer referências ao desenvolvimento de comunidades locais e do país.

De maneira similar, foram observados posicionamentos que indicavam que o país, o mundo, a humanidade ou o futuro deveriam ser sustentados. Nos discursos de quatro das oito organizações analisadas, foram expressas preocupações com a sociedade, sem restringir a sustentabilidade apenas à própria organização e sua área de atuação. Tanto ao se referir a "desenvolvimento sustentável" como ao se tratar de "sociedade sustentável", foram apresentadas preocupações coletivistas, ainda que esses posicionamentos não refletissem qualquer meta da organização ou uma intenção concreta e mensurável.

Porém, foram vários os casos nos quais se observou maior centralidade nas preocupações individualistas nos discursos organizacionais. Cinco organizações afirmaram que a organização, suas práticas, negócios, produção e gestão deveriam ser sustentáveis. Nesses casos, buscaram-se demonstrar preocupações com a atuação da própria empresa e com a possibilidade de ela se tornar, economicamente, viável por mais 
tempo. Assim, a sustentabilidade é entendida apenas como a continuidade da atividade da organização $e$ de seus resultados. Foram percebidas preocupações individualistas também em afirmações de que os resultados, desempenho, crescimento ou lideranças das organizações deveriam ser sustentados ou sustentáveis. Três das organizações demonstraram preocupação com a sustentabilidade dos resultados financeiros da própria organização, ou seja, da sua lucratividade. Nessas situações, a preocupação é predominantemente econômica, sem estabelecer relações com os impactos sociais ou ambientais das atividades da organização.

Nos casos em que se buscou expressar preocupações ambientais, essas estavam muito mais voltadas a interesses individualistas do que coletivistas. No caso da sustentabilidade do uso dos recursos naturais, por exemplo, expresso por três organizações, observou-se que os únicos recursos para os quais se previam o uso sustentável eram aqueles diretamente utilizados pela organização, indicando interesse em preservá-los para uso futuro da própria organização.

\section{Conclusões}

Neste estudo, observou-se que a sustentabilidade, originalmente associada a uma maior integração entre a humanidade e natureza e à manutenção de um equilíbrio dinâmico que permitisse a existência do maior número de espécies possível, pode ser entendida de diferentes maneiras nas organizações. Contudo, buscou-se discutir que o uso desse termo, de maneira indiscriminada, poderia promover um enfraquecimento de sua noção original.

Nos resultados, constatou-se que as oito organizações estudadas apresentaram visões bastante diferentes do conceito de sustentabilidade, assim do que deveria ser sustentado ou sustentável. A maior parte desses conceitos está associada à permanência da própria empresa, atrelando a sustentabilidade ao atendimento dos interesses dos acionistas, às estratégias para o aumento do número de clientes e serviços, ao bom relacionamento com os stakeholders, à redução dos riscos, ou ao aumento da rentabilidade da organização. Mesmo quando foram percebidas preocupações mais coletivistas, não houve clareza sobre como tais posicionamentos poderiam trazer benefícios para todas as formas de vida de maneira sustentável. Foi o que ocorreu quando se relacionou sustentabilidade ao desenvolvimento socioambiental, investimentos socioambientais, responsabilidade social e crescimento econômico. Já as preocupações sociais relacionadas ao conceito de sustentabilidade se resumiram a diferentes formas de investimentos, programas e ações sociais, como a filantropia, a cidadania empresarial, o voluntariado e a responsabilidade social.

Mesmo que esses posicionamentos busquem, de alguma forma, expressar preocupações coletivistas, seja ambiental, seja social, terminam por se restringir a alguns grupos de indivíduos, não se equivalendo a um posicionamento sustentável. Além disso, em nenhum dos casos houve esclarecimento sobre como os impactos da organização sobre o ambiente como um todo (incluindo o social) poderiam ser mantidos ao longo do tempo, sem prejudicar outras espécies ou grupos sociais.

As discussões sobre sustentabilidade podem fomentar reflexões sobre a intervenção humana no ambiente e a busca de caminhos para que essa seja reduzida. Nas organizações, essas discussões poderiam ajudar a definir ações que objetivem mensurar e reduzir a degradação ambiental causada por suas atividades. Esperava-se que os relatórios de sustentabilidade constituíssem um meio de comunicar esses fatos. Restringir esses relatórios à construção de uma imagem positiva da organização, principalmente enfatizando sua lucratividade e os projetos socioambientais apoiados, não só empobrece o conceito de sustentabilidade como adia a constatação de que as mudanças nas organizações na busca desse ideal ainda estão muito lentas.

Os relatórios de sustentabilidade, assim como os materiais contidos nos sítios eletrônicos das organizações, são produzidos com a intenção principal de atrair e manter os investidores. Dessa forma, opta-se, muitas vezes, por relatar exatamente aquilo que eles gostariam de saber e, por isso, o conteúdo central desses materiais foi, em quase todas as organizações, seu resultado econômico. Por isso, tornou-se comum contratar pessoas ou empresas especializadas na construção desses relatórios, de modo a enfatizar o que há de mais positivo a ser descrito e disfarçar tudo aquilo que possa desfavorecer a imagem da organização. Mesmo que as organizações sigam as recomendações da GRI na construção de seus relatórios, ainda há muitas 
brechas nas quais se podem encobrir o que não seja positivo para a imagem da empresa.

$\mathrm{O}$ único relatório que se destacou dos demais foi o da Fundação Bradesco. Pela sua área de atuação e por não ter que atender às mesmas demandas que as outras empresas, principalmente dos investidores, os discursos dessa fundação tiveram como foco central uma descrição das atividades realizadas. Embora não tenha sido relatado, por exemplo, os recursos utilizados, os resíduos produzidos ou sua destinação, a organização se diferenciou das demais por não necessitar se amparar no conceito de sustentabilidade para justificar suas atividades, o que fez com que o uso de tal termo fosse bastante reduzido. As demais organizações estudadas buscaram no termo sustentabilidade uma forma de legitimar sua atuação, provocando um esvaziamento desse conceito e sua utilização muito repetitiva e alegórica. De forma geral, a sustentabilidade foi reduzida ao atendimento dos interesses da própria organização, o que em nada se aproxima do conceito que foi desenvolvido na Biologia.

Ainda que a divulgação de relatórios de sustentabilidade indique que existam alguns avanços na busca de alterações no comportamento das organizações, a maior dessas alterações ainda se restringem a apontar intenções futuras, muitas vezes sem relatos de ações concretas ou o estabelecimento de metas e prazos. Como não há um padrão para a construção desses relatórios e nem a obrigatoriedade de sua divulgação, a tendência é que esse cenário ainda demore a ser alterado.

Ressalta-se, como principal limitação do estudo, os diferentes setores nos quais as organizações atuam, o que leva a um diferente posicionamento das mesmas. Sugere-se que, em estudos futuros, seja analisada a possibilidade de tornar obrigatório esse tipo de relatório, ainda que para empresas de determinados setores ou de grande porte. Também são necessárias mais discussões sobre a adoção de alguma forma de padronização dos relatórios de sustentabilidade, que busquem aprofundar discussões sobre como poderia ser feito um relato claro dos impactos socioambientais das organizações, a destinação de seus resíduos e os recursos utilizados em seu processo produtivo.

\section{REFERÊNCIAS}

AMRAN, A.; LEE, S. P.; DEVI, S. S. The influence of governance structurre and strategic corporate social responsibility toward sustainability reporting quality. Business Strategy and the Environment, USA, jun., 2013.

ANDRADE, J. C. S. Conflito, cooperação e convenções: análise das estratégias sócio-ambientais para a gestão sustentável das plantações de eucalipto da Aracruz Celulose S.A. Organizaçóes \& Sociedade, Salvador, v. 8, n. 20, p. 1-26, 2001.

\section{ASHLEY, P. A. (Coord.) Ética e responsabilidade} social nos negócios. 2. ed. São Paulo: Saraiva, 2005. $340 \mathrm{p}$.

BANCO DO BRASIL. [2010]. Disponível em: <http:// www.bb.com.br/portalbb/home23,116,116,1,1,1,1.bb > . Acesso em: 7 set. 2010 .

Relatório anual 2008: annual report 2008.

Disponível em: < http:/www.bb.com.br/portalbb/ page3,136,3433,0,0,1,8.bb?codigoMenu=198\&codigoNot $\mathrm{icia}=10805 \&$ codigoRet $=214 \&$ bread $=1>$. Acesso em: 10 jun. 2010.

BARDIN, L. Análise de conteúdo. 4. ed. Coimbra: Edições 70, 2004. 281 p.

BAUER, M. W. Análise de conteúdo clássica: uma revisão. In: BAUER, M. W.; GASKELL, G. Pesquisa qualitativa com texto, imagem e som: um manual prático. 3. ed. Petrópolis, RJ: Vozes, 2002. p. 189-217.

BECKER, B. Sustainability assessment: a review of values, concepts, and methodological approaches. Washington: Consultative Group on International Agricultural Research, 1997. 63 p.

BECKER, M. L. Inclusão digital e cidadania: as possibilidades e as ilusões da "solução" tecnológica. Ponta Grossa: UEPG, 2009. 200 p.

BOFF, L. O pecado maior do capitalismo: o risco do ecocídio e do biocídio. [2010]. Disponível em: <http:// www.leonardoboff.com/site/vista/outros/o-pecado.htm $>$. Acesso em: 26 nov. 2010. 
BOWEN, H. R. Social responsibilities of the businessman. New York: Harper, 1953. 276 p.

BRADESCO. [2010]. Disponível em: < http://www. bradesco.com.br/ >. Acesso em: 11 set. 2010.

\section{Relatório de Sustentabilidade 2008.}

[2008]. Disponível em: < http://www.bradescori.com. br/site/conteudo/informacoes-financeiras/relatoriossustentabilidade.aspx?secaold $=723>$. Acesso em: 10 jun. 2010.

CAREGNATO, R. C. A.; MUTTI, R. Pesquisa qualitativa: análise de discurso versus análise de conteúdo. Texto

\&Contexto Enfermagem, Florianópolis, v. 15, n. 4, p. 679-684, out.-dez. 2006.

CARROLL, A. B. Corporate social responsibility.

Business and Society, Chicago, v. 38, n. 3, p. 268-295, Sept. 1999.

CARVALHO, J. L. R.; MACHADO, M. N. M.; MEIRELLES, A. M. Mudanças climáticas e aquecimento global: implicações na gestão estratégica de empresas do setor siderúrgico de Minas Gerais. Cadernos EBAPE. BR, Rio de Janeiro, v. 9, n. 2, artigo 1, jun. 2011.

CAVALCANTI, C. Sustentabilidade da economia: paradigmas alternativos de realização econômica. In:

(Org.). Desenvolvimento e natureza: estudos para uma sociedade sustentável. 2. ed. São Paulo: Cortez, 1998. cap. 9, p. 153-174.

\section{CENTRAIS ELÉTRICAS BRASILEIRAS. [2010].}

Disponível em: <http:/www.eletrobras.com/elb/data/Pages/ LUMIS293E16C4PTBRIE.htm > . Acesso em: 13 set. 2010.

Relatório de Sustentabilidade 2008. [2008].

Disponível em: < http://www.eletrobras.com/elb/data/ Pages/LUMIS9B0F75F9ITEMIDPTBRIE.htm > . Acesso em: 10 jun. 2010

CENTRAIS ELETRICAS DE FURNAS. [2010]. Disponível em: < http://www.furnas.com.br > . Acesso em: 12 set. 2010a.

Relatório socioambiental 2008: o fio que nos une. [2008]. Disponível em: <http://www.furnas.com. br/frmPURelatorioSocioAmbiental.aspx > . Acesso em: 10 jun. 2010.
COMISSÃO MUNDIAL SOBRE MEIO AMBIENTE E DESENVOLVIMENTO. Nosso futuro comum. Rio de Janeiro: FGV, 1991. 430 p.

DIAS, R. Gestão ambiental: responsabilidade social e sustentabilidade. São Paulo: Atlas, 2009. 196 p.

EBERLE, D.; BERENS, G.; LI, T. The impact of interactive corporate social responsability communications on corporate reputation. Journal of Business Ethics, Brandon (Canadá), v. 118, n. 4, p. 731-746, dec. 2013.

FUNDAÇÃO BRADESCO. [2010]. Disponível em: $<$ http://www.fb.org.br/institucional >. Acesso em: 8 set. 2010.

Relatório de atividades 2008. [2008].

Disponível em: <http://www.fb.org.br/Institucional/ InvestimentoseResultados/RelatoriosAnuais/

RelatorioAnual2008.htm >. Acesso em: 10 jun. 2010.

GLADWIN, T. N.; KENNELLY, J. J.; KRAUSE, T.

S. Shifting paradigms for sustainable development: implications for management theory and research.

Academy of Management Review, New York, v. 20, n. 4, p. 874-907, Oct. 1995.

\section{GLOBAL REPORTING INITIATIVE. Diretrizes para} relatório de sustentabilidade. São Paulo, 2006. 47 p. GRI Readers`Choice Awards 2010.

[2010]. Disponível em: <https:/www.globalreporting.org/ resourcelibrary/GRI-Readers-Choice-Awards-2010.pdf > . Acesso em: 10 jun. 2010.

GOMES, G. A. et al. Responsabilidade socioambiental corporativa e indicador de maturidade mediando desempenho estratégico para as organizações. Revista de Ciências da Administração, Florianópolis, v. 12, n. 26, p. 244-269, jan.-abr. 2010.

\section{GUERREIRO RAMOS, A. A nova ciência das}

organizações: uma reconceituação da riqueza das nações. Rio de Janeiro: Editora FGV, 1981.

GRIESSE, M. A. The geographic, political, and economic context for corporate social responsibility in Brazil.

Journal of Business Ethics, Brandon (Canadá), v. 73, n. 1, p. 21-37, june, 2007. 
HIMMELSTEIN, J. L. Looking good and doing good: corporate philanthropy and corporate power. Bloomington: Indiana University Press, 1997. 185 p.

HOFFMAN, A. J.; SANDELANDS, L. E. Getting right with nature: anthropocentrism, ecocentrism, and theocentrism. Organization \& Environment, Tampa, v. 18, n. 2, p. 141-162, June 2005.

\section{INSTITUTO BRASILEIRO DE GOVERNAÇA} CORPORATIVA. Origem da boa governança.

[2010]. Disponível em: < http://www.ibgc.org.br/Secao. aspx?CodSecao=18 >. Acesso em: 25 nov. 2010.

INSTITUTO ETHOS. O que é RSE. [2010]. Disponível em: <http://www1.ethos.org.br/EthosWeb/pt/29/o_que_e_ rse/o_que_e_rse.aspx >. Acesso em: 25 nov. 2010.

ITAIPU BINACIONAL. [2010]. Disponível em: < http:// www.itaipu.gov.br/ > . Acesso em: 14 set. 2010.

\section{Relatório de sustentabilidade 2008}

[2008]. Disponível em: < http://www.itaipu.gov.br/ responsabilidade/relatorios-de-sustentabilidade $>$. Acesso em: 10 jun. 2010.

KEINERT, T. M. M. Introdução: sustentabilidade: entre utopias e inovações. In: KEINERT, T. M. M. (Org.).

Organizações sustentáveis: utopias e inovações. São Paulo: Annablume, 2007. p. 13-18.

LONDON, N. R. Japanese corporate philanthropy.

New York: Oxford University Press, 1991. 137 p.

MICKEY, S. Contributions to anthropocosmic environmental ethics. Worldviews: Global Religions, Culture, and Ecology, Germantown, v. 11, n. 2, p. 226247, 2007.

NAKAYAMA, R. M.; TEIXEIRA, R. M. Esquemas interpretativos de dirigentes e fornecedores com relação a estratégias e ações de responsabilidade social: o caso da empresa O Boticário. Cadernos EBAPE.BR, Rio de Janeiro, v. 10, n. 1, artigo 5, mar. 2012.

NATURA. [2010]. Disponível em: < http://www2.natura. net/NaturaMundi/src/index.asp > . Acesso em: 9 set. 2010.

Relatório anual 2008. [2008]. Disponível em: <http://natura.infoinvest.com.br/ptb/s-15-ptb-2008.html>. Acesso em: 10 jun. 2010.
NOSSA, V. et al. A relação entre o retorno anormal e a responsabilidade social e ambiental: um estudo empírico na Bovespa no período de 1999 a 2006. Brazilian

Business Review, Vitória, p. 121-136, maio-ago. 2009.

PÉREZ-LÓPEZ, D.; MORENO-ROMERO, A.;

BARKEMEYER, R. Exploring the relationship between sustainability reporting and sustainability management practices. Business Strategy and the Environment, USA, dec. 2013.

REDCLIFT, M. Sustainable development: economics and the environment. In: REDCLIFT, M.; SAGE, C.

Sustainable development: local agendas for the Southern Hemisphere. Chichester: J. Wiley, 1994. chap. 2, p. 17-34.

SCHALTEGGER, S.; STURM, A. Ökologieinduzierte entscheidungsprobleme des managements: ansatzpunkte zur ausgestaltung von instrumenten. WWZ Discussion Paper, Basel, n. 8.914, 1989.

SCHMIDHEINY, S. Changing course: a global business perspective on development and the environment. Cambridge: MIT Press, 1992. 374 p.

TENÓRIO, F. G. (Org.). Responsabilidade social empresarial: teoria e prática. Rio de Janeiro: FGV, 2006. 208 p.

VALE. [2010]. Disponível em: <http://www.vale.com/ptbr/Paginas/default.aspx > . Acesso em: 10 set. 2010.

Relatório de sustentabilidade de 2008.

[2008]. Disponível em: <http://www.vale.com/pt-br/ sustentabilidade/relatorio-de-sustentabilidade/paginas/ default.aspx>. Acesso em: 10 jun. 2010.

VIEIRA, F. G. D. et al. Marketing social corporativo: estado da arte e proposição de um esquema conceitual.

Revista de Ciências da Administração, Florianópolis, v. 15, n. 37, p. 37-51, dez. 2013. 